\title{
COMPARED EFFICACY OF RITUXIMAB, ABATACEPT, AND TOCILIZUMAB IN PATIENTS WITH RHEUMATOID ARTHRITIS REFRACTORY TO METHOTREXATE OR ANTI-TNF AGENTS: A SYSTEMATIC REVIEW AND NETWORK META-ANALYSIS
}

Amanda Borges de Oliveira ${ }^{1}$, Alisson Pugliesi ${ }^{2, \star}$, Ricardo Xavier $^{1}$, Licia Maria Henrique da Mota ${ }^{3}$, Manoel Barros Bertolo ${ }^{4}$, Miguel Angel Gonzalez-Gay ${ }^{5}$, Gustavo Citera ${ }^{6}$, Luiz Sérgio Fernandes de Carvalho ${ }^{1}$

1.Fundação de Ensino e Pesquisa em Ciências da Saúde, Brasília (DF), Brazil; 2.Universidade Estadual de Campinas, Campinas (SP), Brazil; 3.Universidade Federal do Rio Grande do Sul, Porto Alegre (RS), Brazil; 4.Universidade de Brasília, Brasília (DF), Brazil; 5.Hospital Universitário Marqués de Valdecilla, Santander (Cantabria), Spain; 6.Instituto de Rehabilitación Psicofísica, Buenos Aires, Argentina.

*Corresponding author: alissonvigano@gmail.com

\section{BACKGROUND}

Disease-modifying antirheumatic drugs (DMARDs), especially methotrexate (MTX) and the biological (bDMARDs) class of tumor necrosis-factor inhibitors have improved the treatment of rheumatoid arthritis (RA), but $1 / 3$ of individuals do not respond to this treatment. Rituximab, abatacept, and tocilizumab are bDMARD options available, but it is unclear whether any of these is superior to the others. The objective of this work was to compare the efficacy of rituximab, tocilizumab, and abatacept in individuals with RA refractory to MTX or anti-TNF.

\section{METHODS}

It is a phase 2-4 randomized controlled trials (RCTs) evaluating patients with RA refractory to MTX or anti-TNF treated with rituximab, abatacept, and tocilizumab compared to controls. Study characteristics, quality, and data were independently assessed by two investigators, in PubMed, Cochrane Library, Embase, Web of Science, Scopus, and LILACS until July 18, 2020. The primary outcome was achieving ACR70 response.

\section{RESULTS}

The meta-analysis included 19 RCTs, with 7,835 patients randomized to the intervention versus control and a mean study duration of 1.2 year. The mean age was 52.3 years, $77.2 \%$ were women, and the mean disease duration was 8.7 years. The hazard ratios (HRs) for achieving an ACR70 response at 6 months were not different among the bDMARDs when compared to placebo (Table 1); however, there was a high heterogeneity. Three factors showing a critical imbalance among the bDMARD classes: baseline HAQ score, study duration, and frequency of anti-TNF treatment in the control arm. To understand the heterogeneity among RCTs, multivariate meta-regression adjusted to these three factors were conducted for the relative risk (RR) for achieving an ACR70 during the study follow-up. Thus, heterogeneity was attenuated $(12=24 \%, p$ for heterogeneity $=0.27)$ and the explanatory power of the model increased $(R 2=85 \%)$. In this model, rituximab did not modify the chance of achieving an ACR70 compared to abatacept $(\mathrm{RR}=1.773,95 \% \mathrm{Cl}=0.113-10.21, \mathrm{p}=0.765)$. In contrast, abatacept was associated with a $\mathrm{RR}=2.217(95 \% \mathrm{Cl}=1.554-3.161$, $\mathrm{p}<0.001$ ) for ACR70 compared to tocilizumab (Table 2). 
Table 1. Indirect comparisons among bDMARDs.

\begin{tabular}{|c|c|c|}
\hline & \multicolumn{2}{|c|}{ ACR70 response rate, $\mathrm{HR}(95 \% \mathrm{Cl}), \mathrm{p}$ value } \\
\hline & All trials & Excluding one trial from each class* \\
\hline Abatacept vs. rituximab & $1.017(0.373,2.845) \cdot p=0.84$ & $1.029(0.324,2.959), p=0.88$ \\
\hline Tocilizumab vs. rituximab & $0.791(0.254,2.461), p=0.32$ & $0.811(0.224,2.618), p=0.40$ \\
\hline Tocilizumab vs. abatacept & $0.806(0.263,2.505), p=0.37$ & $0.814(0.237,2.614), p=0.43$ \\
\hline Abatacept vs. anti-TNF & $1.043(0.422,2.242), p=059$ & $1.063(0.402,2.492), p=0.56$ \\
\hline Tocilizumab vs. anti-TNF & $0.839(0.373,3.804), p=045$ & $0.814(0.331,4.007), p=0.41$ \\
\hline Rituximab vs. anti-TNF & $1.059(0339,2.581), p=0.51$ & $1.042(0.305,2.886), p=0.67$ \\
\hline Abatacept vs. placebo & $3.423(1.422,8.709), p<0001$ & $3.438(1.413,8.762), p<0.001$ \\
\hline Tocilizumab vs. placebo & $2.765(1.240,6.692), p=0.009$ & $2.525(1.096,6.921) \cdot p=0.015$ \\
\hline Rituximab vs. placebo & $3.494(1.530,8.658), p<0.001$ & $3.509(1.522,8.676), p<0.001$ \\
\hline
\end{tabular}

Table 2. Meta-regression models for achieving ACR70.

\begin{tabular}{|c|c|c|c|c|}
\hline & \multirow[b]{2}{*}{$\mathrm{RR}$} & \multicolumn{2}{|c|}{$95 \% \mathrm{Cl}$} & \multirow[b]{2}{*}{$\mathrm{p}$} \\
\hline & & $\begin{array}{l}\text { Lower } \\
\text { bound }\end{array}$ & $\begin{array}{l}\text { Upper } \\
\text { bound }\end{array}$ & \\
\hline \multicolumn{5}{|l|}{ Model 1} \\
\hline Mean baseline HAQ (each additional $0.1 \mathrm{pd}$ ) & 2.0433 & 1.0328 & 14.4460 & 0.028 \\
\hline \multicolumn{5}{|l|}{ Model 2} \\
\hline Background anti-TNF in control arm (yes vs no) & 0.3166 & 0.1345 & 0.7460 & 0.009 \\
\hline \multicolumn{5}{|l|}{ Model 3} \\
\hline Follow-up time (each additional 1 month) & 0.9714 & 0.9522 & 0.9920 & 0.007 \\
\hline \multicolumn{5}{|l|}{ Model 4} \\
\hline Mean baseline HAQ (each additional 0.1 point) & 2.0332 & 1.0141 & 14.6164 & 0.045 \\
\hline Background anti-TNF in control arm (yes vs. no) & 0.2187 & 0.1341 & 0.3567 & $<0.001$ \\
\hline Follow-up time (each additional 1 month) & 0.9763 & 0.9504 & 9899 & 0.016 \\
\hline ABA vs RTX & 1.7736 & 0.1134 & 102.165 & 0.625 \\
\hline ABA vs TCZ & 2.2171 & 1.5541 & 3.1614 & $<0.001$ \\
\hline
\end{tabular}

\section{CONCLUSION}

In the network meta-analysis, there was no significant difference among tocilizumab, abatacept, and rituximab in achieving an ACR70. Based on the result of multivariate meta-regressions, if the conditions of the RCTs were similar, we estimate that abatacept could increase the chance of reaching an ACR70 response by 2.2-fold compared to tocilizumab.

\section{KEYWORDS}

Rheumatoid arthritis, Network meta-analysis, Rituximab, Tocilizumab, Abatacept. 